\title{
Familial Clustering of Hypereosinophilic Diseases Treated with Mepolizumab: a Case Report from Japan
}

\author{
${ }^{1}$ Department of Allergy and Respiratory Medicine, Sutoh Hospital, Annaka, Japan \\ ${ }^{2}$ Department of Surgery, Sutoh Hospital, Annaka, Japan
}

\section{KEY WORDS}

anti-IL-5 antibody; eosinophilic asthma; eosinophilic granulomatosis with polyangiitis; hypereosinophilic syndrome; mepolizumab

\author{
Corresponding author \\ Motohiro Kurosawa \\ Department of Allergy and Respiratory Medicine \\ Sutoh Hospital, 3532-5 Annaka \\ Gunma 379-0116, Japan \\ Phone: +81273823131 \\ Fax: +81273826568 \\ E-mail: motohiro@kl.wind.ne.jp
}

Doi

10.23822/EurAnnACI.1764-1489.112

\begin{abstract}
Summary
We describe a female diagnosed with non-allergic asthma. On March 24, 2016, examination of the skin-biopsy specimen revealed dense eosinophilic infiltration, and the Fip-1-like 1-platelet-derived growth factor receptor a fusion gene in peripheral blood mononuclear cells was negative. She was diagnosed with idiopathic hypereosinophilic syndrome. She was treated with intravenous methylprednisolone (MPSL), and subsequent oral MPSL. Then, she started to receive a monthly mepolizumab in June 2016, and successfully withdrew from daily use of oral MPSL. The patient has a mother diagnosed with non-allergic asthma. In February 2005, she was diagnosed with eosinophilic granulomatosis with polyangiitis because of elevated antineutrophil myeloperoxidase antibodies, and the skin-biopsy specimen findings. She started to receive a monthly mepolizumab in June 2016. Corticosteroid therapy was successfully withdrawn. To our knowledge, this is the first case report suggesting mepolizumab may be a useful treatment for familial clustering of hypereosinophilic diseases.
\end{abstract}

\section{Introduction}

Eosinophilic granulomatosis with polyangiitis (EGPA) (formerly known as Churg-Strauss syndrome) and idiopathic hypereosinophilic syndrome (HES) are rare eosinophilic disorders. Definitive diagnosis of EGPA relies on the demonstration of vasculitis in tissue-biopsy specimen (1). HES is defined by unexplained blood eosinophilia above $1500 / \mu \mathrm{L}$ on 2 separate occasions at least 1 month apart and evidence of end-organ involvement attributed to eosinophilia (2). Although it is quite rare that EGPA and/or HES are seen in several members of the same family, familial clustering of hypereosinophilic diseases has been reported in medical literature since the early 1900 s $(3,4)$. In these families, the distribution of eosinophilia was suggested to involve autosomal dominant inheritance (5). On the other hand, Ota et al. (6) reported 3 siblings who suffered from marked eosinophilia, 2 of them were diagnosed with EGPA and 1 was with HES, and suggested they may be affected by another type of familial eosinophilia distinguishable from those previously described.

We describe a case of familial clustering of hypereosinophilic diseases treated with mepolizumab, a humanized $\mathrm{IgG}_{1}$ mono- clonal antibody that prevents human interleukin 5 (IL-5) from binding to the IL-5 receptor (7), and suggest mepolizumab may be a useful treatment for familial clustering of hypereosinophilic diseases.

\section{Materials and methods}

Mepolizumab was administered subcutaneously every 4 weeks at a dose of $100 \mathrm{mg}$. Asthma Control Test (ACT) (8), peripheral blood eosinophils, forced expiratory volume in 1 second $\left(\mathrm{FEV}_{1}\right)$ and drug safety were assessed at each visit; fractional exhaled nitric oxide (FeNO) was not assessed, because no significant differences were found in the DREAM trial (9). FEV values were reported as a percentage of predicted values, using a spirometer (FUKUDA-77, Fukuda Denshi, Tokyo, Japan), and the best of 3 expiratory maneuvers was recorded. The scores in the ACT range from 5 (absence of disease control) to 25 (total disease control). The cut off value for controlled asthma (ACT $\geq 20$ ) was chosen according to previous studies cut off value (10). Peripheral blood eosinophils were counted automatically by the Beckman Coulter counter (Beckman Coulter, Fullerton, 
CA, USA) and MAXM A/L system (Beckman Coulter). Serum levels of IgE were measured using the CAP system (Phadia, Uppsala, Sweden), and antineutrophil myeloperoxidase (MPO) antibodies were measured by an enzyme-linked immunosorbent assay (ELISA) analysis (Orgentec Diagnostika GmbH, Mainz, Germany), and the analyses and cut-off procedures were performed according to the manufacturer's instructions (reference $<3.5 \mathrm{U} / \mathrm{mL}$ ). De Lavareille et al. (11) reported that serum levels of thymus and activation-regulated chemokine (TARC) may represent a precious and discriminative diagnostic tool for the patients with lymphocytic HES, and we measured TARC concentration by an ELISA kit (R\&D Systems, Minneapolis, USA) as reported (12). The Fip-1-like 1-platelet-derived growth factor receptor $\alpha$ (FIP1L1-PDGFRA) fusion gene in peripheral blood mononuclear cells was analyzed by the fluorescence in situ hybridization method as reported (13).

This study was performed in accordance with the Good Clinical Practice guidelines, the ethics principles outlined in the Declaration of Helsinki 2008, in accordance with the Institutional Ethics Committee of Sutoh Hospital (IRB\#20160050). Written informed consent was obtained from each individual before the study commenced.

\section{Case report}

A 56-year-old female was diagnosed with bronchial asthma by the author in April 1994. She had non-allergic asthma phenotype, confirmed by low serum total $\mathrm{IgE}$ levels $(71 \mathrm{IU} / \mathrm{mL})$ and negative results of serum specific IgE for common inhaled allergens, including molds, and Dermatophagoides farinae and petronyssinus. The diagnosis was confirmed using the Global Initiative for Asthma (GINA) guidelines (14). Her asthma was corticosteroid-dependent and met the American Thoracic Society criteria for a diagnosis of refractory asthma (15). Her basal therapy regimen had included daily use of inhaled fluticasone $800 \mu \mathrm{g}$ (maximum recommended dose in Japan) and inhaled salmeterol $100 \mu \mathrm{g}$, and near continuous ( $\geq 50 \%$ of year) $5 \mathrm{mg} /$ day corticosteroids orally. She had experienced at least 2 or more asthma exacerbations each year that were treated with $300 \mathrm{mg}$ hydrocortisone administered intravenously. Blood eosinophil

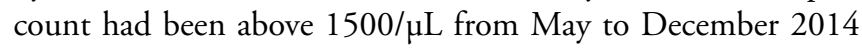
with recurrent asthma exacerbations each month, which were treated with $30 \mathrm{mg}$ prednisolone orally for 3 days or required a visit to the emergency department with $200 \sim 300 \mathrm{mg}$ hydrocortisone intravenous administration. However, she didn't require hospitalizations. Blood eosinophil count decreased to $836 / \mu \mathrm{L}$ in January 2015 , and asthma was well controlled with therapy consisting of fluticasone / salmeterol $125 \mu \mathrm{g} / 25 \mu \mathrm{g}$ inhaler 4 puffs/day and $5 \mathrm{mg}$ prednisolone orally for a while. On September 4, 2015, she visited our clinic because of moderate asthma exacerbation. Blood eosinophil count was $1187 / \mu \mathrm{L}$, and she was given $250 \mathrm{mg}$ aminophylline and $300 \mathrm{mg}$ hydrocortisone infusion. Since then, her asthma became unstable. On October 2, 2015, blood eosinophil count increased $(1843 / \mu \mathrm{L})$ with worsening of asthma requiring $300 \mathrm{mg}$ hydrocortisone infusion, and since then, she was treated with fluticasone / salmeterol $250 \mu \mathrm{g} / 25 \mu \mathrm{g}$ inhaler 4 puffs/day and $5 \mathrm{mg}$ prednisolone orally. Eosinophil count remained above $1500 / \mu \mathrm{L}$ without clinical manifestations of end-organ involvement except asthma. On March 24, 2016, she visited the emergency department with dyspnea. She also had low-grade-fever, general fatigue, anosmia, nasal congestion, and eczematous lesions of the skin, but not peripheral limb neuropathy. Blood eosinophil count was 3416/ $\mu \mathrm{L}$. Computed tomography (CT) scan of nasal sinuses showed bilateral opacities. She was thus hospitalized for a detailed workup (figure 1).

Examination of the skin-biopsy specimen revealed dense eosinophilic infiltration of the dermis and subcutis. Stool microscopy did not identify any ova, cysts or parasites, and serum antibody tests for the parasites Fasciola hepatica, Strongyloides spp., Trichinella spp., Taenia solium, Schistosoma mansoni and Toxocara canis were negative. Specific IgE antibodies to Aspergillus fumigatus and Candida albicans were negative. Serum Aspergillus antigen was negative. Endoscopic examinations and whole-body CT scan examinations were normal, and blood tests for tumor markers were negative, ruling out secondary causes of eosinophilia. Serum levels of total $\mathrm{IgE}$ and C-reactive protein (CRP) were $102 \mathrm{IU} / \mathrm{mL}$ and $36.6 \mathrm{mg} / \mathrm{L}$, respectively. Antineutrophil MPO antibodies were negative $(<0.5 \mathrm{U} /$ $\mathrm{mL}$ ). Serum TARC concentration was increased to $1270 \mathrm{pg} /$ $\mathrm{mL}$ (range in healthy controls: $7-470 \mathrm{pg} / \mathrm{mL}$ ). The patient was negative for the FIP1L1-PDGFRA fusion gene in peripheral blood mononuclear cells. However, flow cytometric analysis to look for IL-5 producing clonal lymphocyte subpopulations and bone marrow biopsy could not be performed. Given the above findings, she was diagnosed with idiopathic HES based on the criteria (2).

She was given methylprednisolone (MPSL) $500 \mathrm{mg} /$ day infusion for 3 days and then oral MPSL $24 \mathrm{mg} /$ day; skin lesions completely resolved, eosinophil count decreased $(778 / \mu \mathrm{L})$, serum CRP levels dropped to normal levels. MPSL dose was tapered gradually to $8 \mathrm{mg} /$ day. On April 15, 2016, eosinophil count was $276 / \mu \mathrm{L}$ and she was discharged.

Her baseline medication included oral MPSL $4 \mathrm{mg} /$ day and fluticasone / salmeterol $125 \mu \mathrm{g} / 25 \mu \mathrm{g}$ inhaler 4 puffs/day (maximum recommended inhaled dose in Japan). She came to our clinic on June 24, 2016 as a regular visit. Blood eosinophil count, $\mathrm{FEV}_{1}(\%)$ value, and the ACT score were $223 / \mu \mathrm{L}, 68.44 \%$, and 21 , respectively. She started to receive a monthly mepolizumab administration. Blood eosinophil count decreased to $44 / \mu \mathrm{L}$ on July 22, 2017. Oral MPSL was stopped, and FEV (\%) value and the ACT score gradually improved up to $76.45 \%$ and 25 on 
Figure 1 - Clinical course of a 56-year-old female diagnosed with idiopathic hypereosinophilic syndrome. After start of monthly mepolizumab administration, she withdrew from daily use of oral methylprednisolone in parallel with stable clinical symptoms.

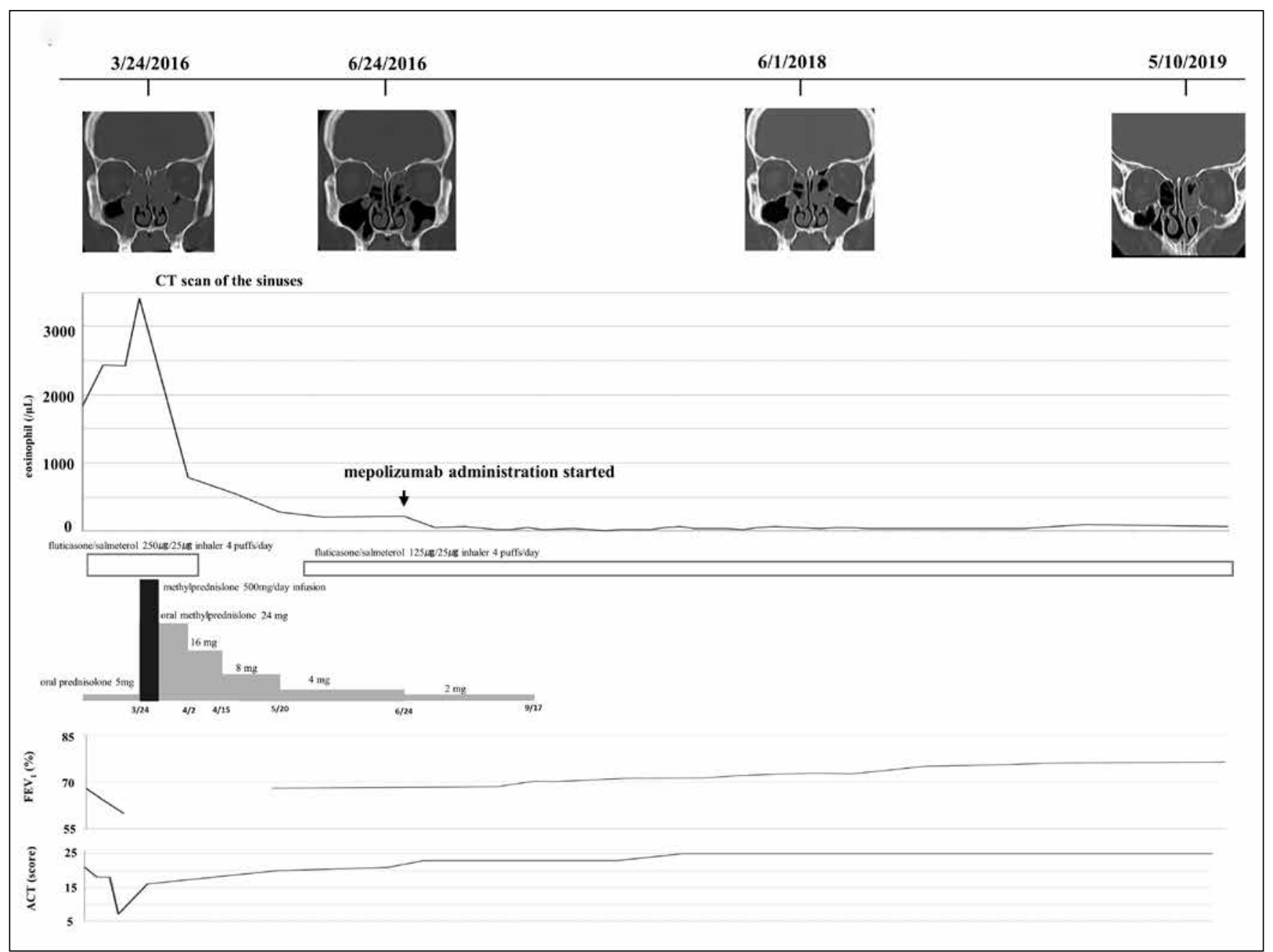

May 10, 2019. Her asthma control has been good, and no side effects of mepolizumab have been observed until May 2019. The patient has an 81-year-old mother, diagnosed with bronchial asthma by the author in September 1994. She had non-allergic asthma with serum total $\mathrm{IgE}$ level $45 \mathrm{IU} / \mathrm{mL}$, and negative results of serum specific $\mathrm{IgE}$ for common inhaled allergens. The diagnosis was confirmed using the GINA guidelines (14). In February 2005, she experienced fever and weight loss with palpable purpura of the skin, arthralgia, myalgia, tenderness of four limbs, and multiplex mononeuritis. Antineutrophil MPO antibodies were elevated $(10 \mathrm{U} / \mathrm{mL})$, and the skin-biopsy specimen revealed small-vessel vasculitis. Given these findings, she was diagnosed with EGPA based on the American College of Rheumatology criteria (1). As she had been treated for a very long time with corticosteroids, she had a very heavy burden of corticosteroids side effects, including hyperglycemia.

She visited our clinic on September 1, 2014 with recent worsening of asthma symptoms. Blood eosinophil count was $410 / \mu \mathrm{L}$, and CT scan of the sinuses confirmed chronic sinusitis. Serum total IgE level was $80 \mathrm{IU} / \mathrm{mL}$. She was treated with fluticasone / salmeterol $125 \mu \mathrm{g} / 25 \mu \mathrm{g}$ inhaler 4 puffs/day and $10 \mathrm{mg}$ prednisolone orally. She came to our clinic with her daughter on June 24, 2016 as a regular visit. Blood eosinophil count, glycated hemoglobin $\left(\mathrm{HbA}_{1 \mathrm{C}}\right)$ level, $\mathrm{FEV}_{1}(\%)$ value, and the ACT score were $220 / \mu \mathrm{L}, 7.4 \%, 53.96 \%$, and 18 , respectively. She started to receive a monthly mepolizumab administration because her asthma was corticosteroid-dependent. Then, corticosteroid therapy was successfully withdrawn in parallel with sustained 
reduction in blood eosinophil count and $\mathrm{HbA}_{1 \mathrm{C}}$ level. $\mathrm{FEV}_{1}$ (\%) value and ACT score gradually improved up to $65.38 \%$ and 25 on May 10, 2019. However, the findings of CT scan of the sinuses remained unchanged (figure 2). She has been stable in asthma symptoms, and no side effects of mepolizumab have been observed until May 2019. Clinical symptoms of EGPA, such as palpable purpura of the skin, mononeuritis multiplex and chronic sinusitis did not change.

\section{Discussion}

Eosinophilia is caused by several diseases, including allergic reaction, parasitic and viral infections, malignancies. EGPA and
HES are known to be associated with peripheral blood eosinophilia. However, they are clearly distinguished from allergic reactions because they have distinctive clinical features, namely organ damage due to eosinophilia $(16,17)$. Although EGPA and/or HES are rarely observed in the same family, familial clustering of hypereosinophilic diseases has been reported in medical literature since 1909 (3-6). In this case report, we describe a case of familial clustering of hypereosinophilic diseases, EGPA and idiopathic HES, diagnosed according to current clinical criteria $(1,2)$, and both of them were treated with mepolizumab. Currently available therapies for eosinophil-associated diseases including corticosteroids, and immunomodulatory and cytotoxic therapies have variable efficacy and significant toxicity,

Figure 2 - Clinical course of an 81-year-old female, mother of the patient in figure 1, diagnosed with eosinophilic granulomatosis with polyangiitis. After start of monthly mepolizumab administration, she withdrew from daily use of prednisolone. In parallel with sustained reduction in blood eosinophil count and HbA1C level, FEV1 (\%) values and ACT scores gradually improved with mepolizumab administration.

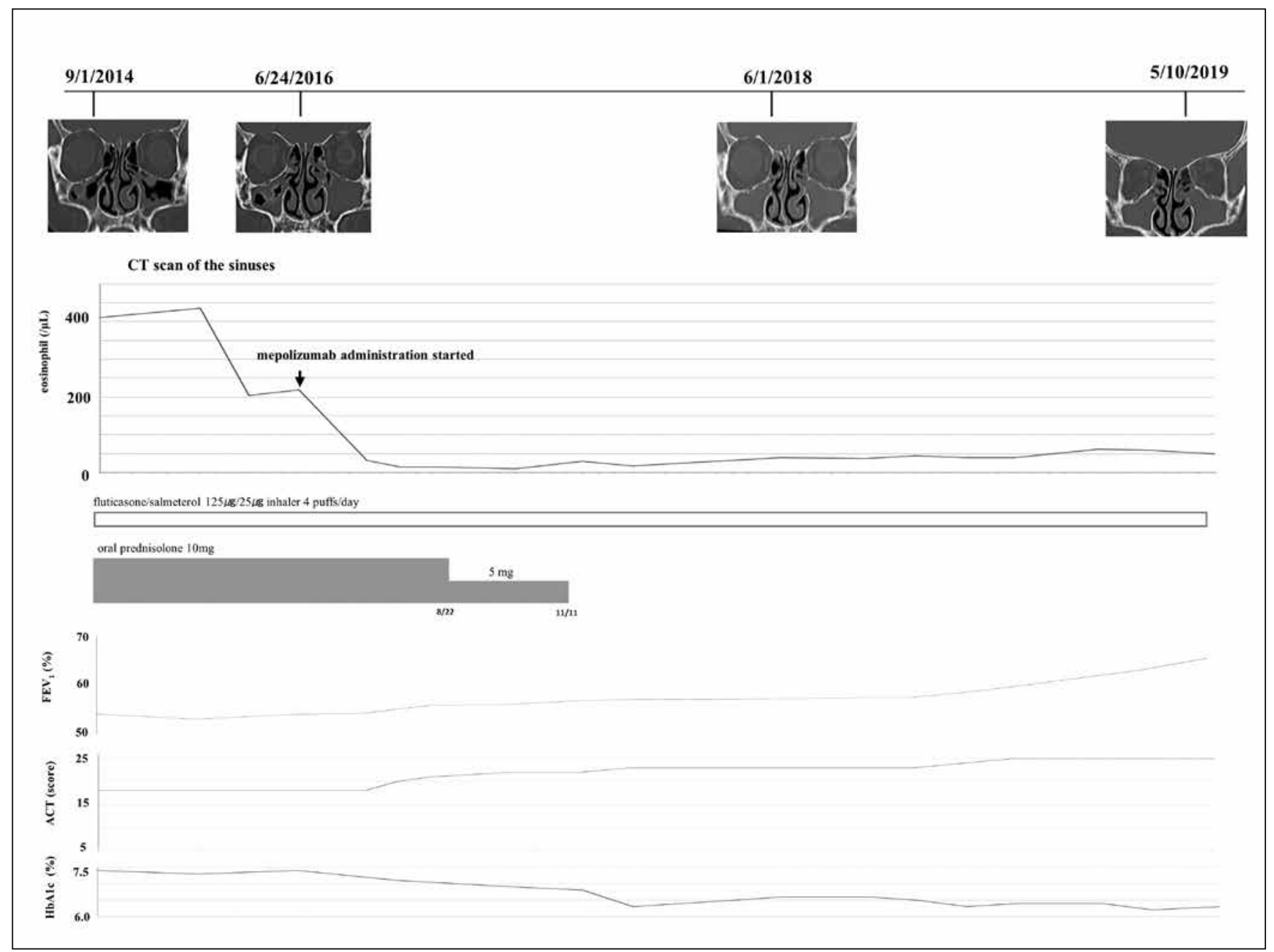


and safe and effective therapies that target eosinophils are clearly needed (18).

IL-5 plays a key role on chemotaxis, differentiation, activation, and survival of eosinophils (19), and antagonism of IL-5 is considered a therapeutic target in patients with eosinophilic disorders. In November 2015, the US Food and Drug Administration (FDA) committee approved mepolizumab for use in patients older than 18 years with severe eosinophilic asthma at a dose of $100 \mathrm{mg}$ administered once every 4 weeks (20), and in December 2015, the European Medicines Agency (EMA) approved a marketing authorization valid throughout the European Union as medicine under additional monitoring (21). In June 2016, mepolizumab was approved in Japan for use in patients with severe asthma aged 12 years and older with an eosinophilic phenotype or with oral corticosteroid dependent asthma. In December 2017, the US FDA expanded the use to treat adult patients with EGPA, based on the results of the phase III trial report (22), with subsequent approval in May 2018 in Japan.

Advances in diagnostic approaches and therapeutic options for HES have prompted reevaluation of the definition and classification of HES. Some limitations of the diagnostic criteria established by Chusid et al. in 1975 (23) are present, and the revised-classification of HES into myeloproliferative, lymphocytic, and other forms is considered to be more useful in guiding clinical evaluation and therapeutic decisions (2). Tyrosine kinase inhibitor imatinib mesylate has been shown to be useful in myeloproliferative HES resulting from the fusion of the FIP1L1-PDGFRA and Fip1-like 1 genes $(24,25)$. However, currently available therapies, including corticosteroids and imatinib, have variable efficacy and significant toxicity (26). On the other hand, mepolizumab has been suggested to be an effective and safety management of lymphocytic $\operatorname{HES}(27,28)$. Mepolizumab has a long-term safety for the treatment of lymphocytic HES $(29,30)$.

We describe a case of familial clustering of hypereosinophilic diseases treated with mepolizumab for 3 years in the present study. A 56-year-old female diagnosed with idiopathic HES was treated with 3 day-intravenous administrations of MPSL, and subsequent oral MPSL. After starting mepolizumab administration, she was able to stop daily therapy with oral MPSL, which was consistent with the results of a previous report (31). $\mathrm{FEV}_{1}(\%)$ value and the ACT score gradually improved. The limitation of this study is lack of low cytometric and bone marrow evaluations to rule out some hematological diseases in the patient, however her clinical symptoms have been stable and no side effects have been observed during the 3 years of treatment. Her clinical response points to the diagnosis, and she will keep the therapy. The patient has an 81-year-old mother diagnosed with EGPA. After beginning mepolizumab administration, she was able to stop daily therapy with oral prednisolone, which was consistent with the results of a previous report (32). In par- allel with sustained reduction in blood eosinophil count, $\mathrm{FEV}_{1}$ (\%) value and ACT score gradually improved as reported about asthmatic findings $(33,34)$. Her asthma symptoms have been stable and no side effects have been observed during the 3 years of the treatment. However, clinical symptoms of EGPA, with the exception of asthmatic symptoms, remained unchanged, which was consistent with previous reports (32). The lack of efficacy of mepolizumab on the non-asthmatic symptoms may be due to the dose of mepolizumab. Namely, the patient started to receive a monthly mepolizumab administration at a dose of $100 \mathrm{mg}$ in June 2016, and continued it for 3 years. On the other hand, the FDA approval of mepolizumab in adult patients affected by EGPA was at a dose of $300 \mathrm{mg}$ administered subcutaneously every 4 weeks, and the same dose was approved for EGPA in Japan. Further studies are needed.

Needless to say, this case report has limitations. This study is an open-label, non-controlled trial, and definite proof that mepolizumab is responsible for these improvements cannot be ensured. However, to our best knowledge, this is the first report of familial clustering of hypereosinophilic diseases, idiopathic HES and EGPA, treated with mepolizumab for 3 years, suggesting mepolizumab may be a useful treatment for familial clustering of hypereosinophilic diseases.

\section{Conclusions}

This case report showed a favorable long-term safety and clinical efficacy of mepolizumab in familial clustering of hypereosinophilic diseases.

\section{Acknowledgements}

The authors would like to thank Junya Maehata, BSc, for his assistance in assembling figures.

\section{Conflict of interests}

The authors declare that they have no conflict of interest.

\section{Ethical disclosures}

Institutional ethics committee approved this study and written informed consent from each individual was obtained before the study.

\section{References}

1. Masi AT, Hunder GG, Lie JT, Michel BA, Bloch DA, Arend WP, et al. The American College of Rheumatology 1990 criteria for the classification of Churg-Strauss syndrome (allergic granulomatosis and angitis). Arthritis Rheum 1990; 33(8):1094-1100.

2. Valent P, Klion AD, Horny H-P, Roufosse F, Gotlib J, Weller PF, et al. Contemporary consensus proposal on criteria and classification 
of eosinophilic disorders and related syndromes. J Allergy Clin Immunol 2012; 130(3):607-612.e9.

3. Gaugain M. Un cas d'eosinophilie familiare. Sem Med 1909; 29:329.

4. Naiman JL, Oski FA, Allen FH Jr, Diamond LK. Hereditary eosinophilia: report of a family and review of the literature. Am J Hum Genet 1964; 16(2):195-203.

5. Lin AY, Nutman TB, Kaslow D, Mulvihill JJ, Fontaine L, White BJ, et al. Familial eosinophilia: clinical and laboratory results on a U.S. kindred. Am J Med Genet 1998; 76(3):229-237.

6. Ota M, Takenaka K, Takahashi M, Nagasaka K. Eosinoplilia with organ involvement in 3 siblings. Jpn J Clin Immunol 2012; 35(6):533-538.

7. Flood-Page P, Menzies-Gow A, Phipps S, Ying S, Wangoo A, Ludwig MS, et al. Anti-IL-5 treatment reduces deposition of ECM proteins in the bronchial subepithelial basement membrane of mild atopic asthmatics. J Clin Invest 2003; 112(7):1029-1036.

8. Korn S, Both J, Jung M, Hubner M, Taube C, Buhl R. Prospective evaluation of current asthma control using ACQ and ACT compared with GINA criteria. Ann Allergy Asthma Immunol 2011; 107(6):474-479.

9. Pavord ID, Korn S, Howarth P, Bleecker ER, Buhl R, Keene ON, et al. Mepolizumab for severe eosinophilic asthma (DREAM): a multicentre double-blind, placebo-controlled trial. Lancet 2012; 380(9842):651-659.

10. Jia CE, Zhang HP, Lv Y, Liang R, Jiang YQ, Powell H, et al. The Asthma Control Test and Asthma Control Questionnaire for assessing asthma control: systemic review and meta-analysis. J Allergy Clin Immunol 2013; 131(3):695-703.

11. De Lavareille A, Roufosse F, Schmid-Grendelmeier P, Roumier AS, Schandene L, Cogan E, et al. High serum thymus and activation-regulated chemokine levels in the lymphocytic variant of the hypereosinophilic syndrome. J Allergy Clin Immunol 2002; 110(3):476-479.

12. Sugawara N, Yamashita T, Ote Y, Miura M, Terada N, Kurosawa M. TARC in allergic disease. Allergy 2002; 57(2):180-181.

13. Pardanani A, Ketterling RP, Brockman SR, Flynn HC, Paternoster SF, Shearer BM, et al. CHIC2 deletion, a surrogate for FIP1L1-PDGFRA fusion, occurs in systemic mastocytosis associated with eosinophilia and predicts response to imatinib mesylate therapy. Blood 2003; 102(9):3093-3096.

14. Global Initiative for Asthma (GINA). Global strategy for asthma management and prevention. http//www.ginasthma.org/local/uploads/files/GINA_Report_2015. Accessed May 2015.

15. American Thoracic Society. Proceedings of the ATS workshop on refractory asthma: current understanding, recommendations, and unanswered question. Am J Respir Crit Care Med 2000; 162(6):2341-2351.

16. Pagnoux C. Churg-Strauss syndrome: evolving concepts. Discov Med 2010; 9(46):243-252.

17. Gleich GJ, Leiferman KM. The hypereosinophilic syndromes: current concepts and treatments. Br J Haematol 2009; 145(3):271285.

18. Bochner BS, Book W, Busse WW, Butterfield J, Furuta GT, Gleich GJ, et al. Workshop report from the National Institute of Health Taskforce on the Research Needs of Eosinophil-Associated Diseases (TREAD). J Allergy Clin Immunol 2012; 130(3):587-596.
19. Sanderson CJ. Interleukin-5, eosinophils, and disease. Blood 1992; 79(12):3101-3109.

20. U.S. Food and Drug Administration. FDA approves Nucala to treat severe asthma. FDA News Release. 2015 November 4. Available from http://www.fda.gov/NewsEvents/Newsroom/PressAnnouncements/ucm471031.htm. Accessed January 10, 2016.

21. http://www.ema.europa.eu/ema. Nucala authorization details [updated on 15/04/2016]. Available from: http://www.ema.europa.eu/ ema/index.jsp?curl=pages/medicines/human/medicines/003860/ human_med_. Accepted May 5, 2016.

22. Wechsler ME, Akuthota P, Jayne D, Khoury P, Klion A, Langford CA, et al. Mepolizumab or placebo for eosinophilic granulomatosis with polyangiitis. N Engl J Med 2017; 376(20):1921-1932.

23. Chusid MJ, Dale DC, West BC, Wolff SM. The hypereosinophlic syndrome: analysis of fourteen cases with review of the literature. Medicine (Baltimore) 1975; 54(1):1-27.

24. Gleich GJ, Leiferman KM, Pardanani A, Tefferi A, Butterfield JH. Treatment of hypereosinophilic syndrome with imatinib mesilate. Lancet 2002; 359(9317)1577-1578.

25. Cools J, DeAngelo DJ, Gotlib J, Stover EH, Legare RD, Cortes J, et al. A tyrosine kinase created by fusion of the PDGFRA and FIP1L1 genes as a therapeutic target of imatinib in idiopathic hypereosinophilic syndrome. N Engl J Med 2003; 348(13):12011214.

26. Ogbogu PU, Bochner BS, Buterfield JH, Gleich GJ, Huss-Marp J, Kahn JE, et al. Hypereosinophilic syndrome: a multicenter, retrospective analysis of clinical characteristics and response to therapy. J Allergy Clin Immonol 2009; 124(6):1319-1325.

27. Rothenberg ME, Klion AD, Roufosse FE, Kahn JE, Weller PF, Simon HU, et al. Treatment of patients with the hypereosinophilic syndrome with mepolizumab. N Engl J Med 2008; 358(12):12151228.

28. Busse WW, Ring J, Huss-Marp J, Kahn JE. A review of treatment with mepolizumab, an anti-IL-5 mAb, in hepeyeosinophilic syndrome and asthma. J Allergy Clin Immunol 2010; 125(4):803813.

29. Roufosse FE, Kahn J-E, Gleich GJ, Schwartz LB, Singh AD, Rosenwasser LJ, et al. Long-term safety of mepolizumab for the treatment of hypereosinophilic syndrome. J Allergy Clin Immunol 2013; 131(2):461-467.

30. Kuang FL, Fay MP, Ware JA, Wetzler L, Holland-Thomas N, Brown T, et al. Long- term clinical outcomes of high dose mepolizumab treatment for hypereosinophilic syndrome. J Allergy Clin Immunol Pract 2018; 6(5):1518-1527.

31. Roufosse F, De Lavareille A, Schandene L, Cogan E, Georgelas A, Wagner L, et al. Mepolizumab as corticoid-sparing agent in lymphocytic variant hypereosinophilic syndrome. J Allergy Clin Immunol 2010; 126(4):828-835.

32. Kim S, Marigowda G, Oren E, Israel E, Wechsler ME. Mepolizumab as a steroid-sparing option in patients with Churg-Strauss syndrome. J Allergy Clin Immunol 2010; 125(6):1336-1343.

33. Ortega HG, Liu MC, Pavord ID, Brusselle GG, FitzGerald JM, Chetta A, et al. Mepolizumab treatment in patients with severe eosinophilic asthma. N Engl J Med 2014; 371(13):1198-1207.

34. Kurosawa M, Sutoh E: Prospective open-label study of 48-week subcutaneous administration of mepolizumab in Japanese patients with severe eosinophilic asthma. J Investig Allergol Clin Immunol 2019; 29(1):40-45. 